\title{
An unexpected diagnosis of pericardial effusion
}

\author{
David Sotello MD, Alexander Trujillo MD, Suthipong Soontrapa MD \\ Jennifer Harris CNMT, Gary Meyerrose MD
}

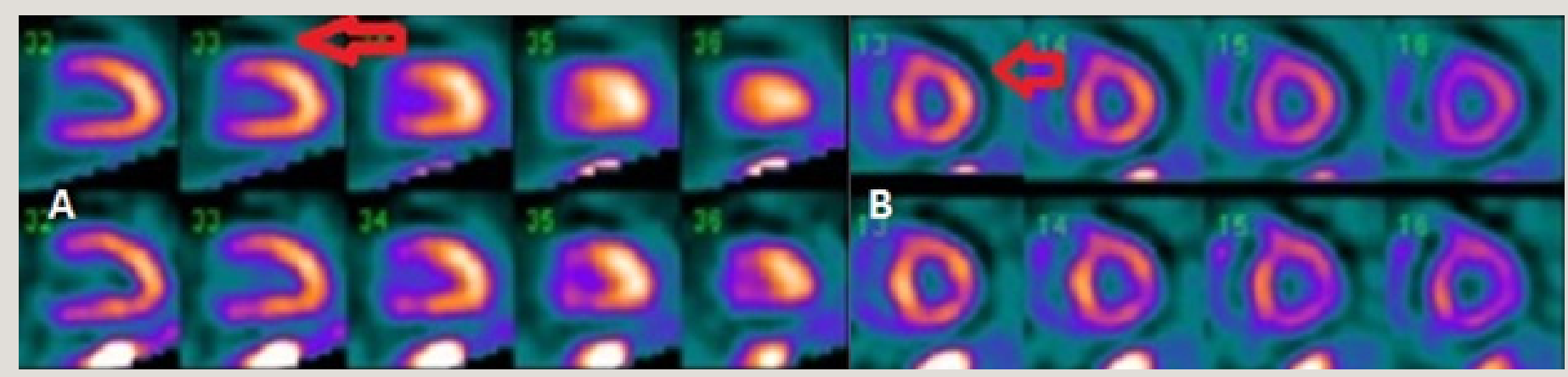

Figure 1 Nuclear myocardial perfusion images with TC-99m. The images displayed on the top row are stress images, and the images displayed on the bottom row are the resting images. Long axis $(A)$ and short axis $(B)$ images seen here have a surrounding area of decreased radiopharmaceutical uptake around the left ventricle (arrows) due to the presence of a moderate sized pericardial effusion. This halo of decreased tracer uptake is seen more clearly than usual due to increased lung uptake of radiopharmaceutical resulting from the elevated left ventricular end diastolic pressure.

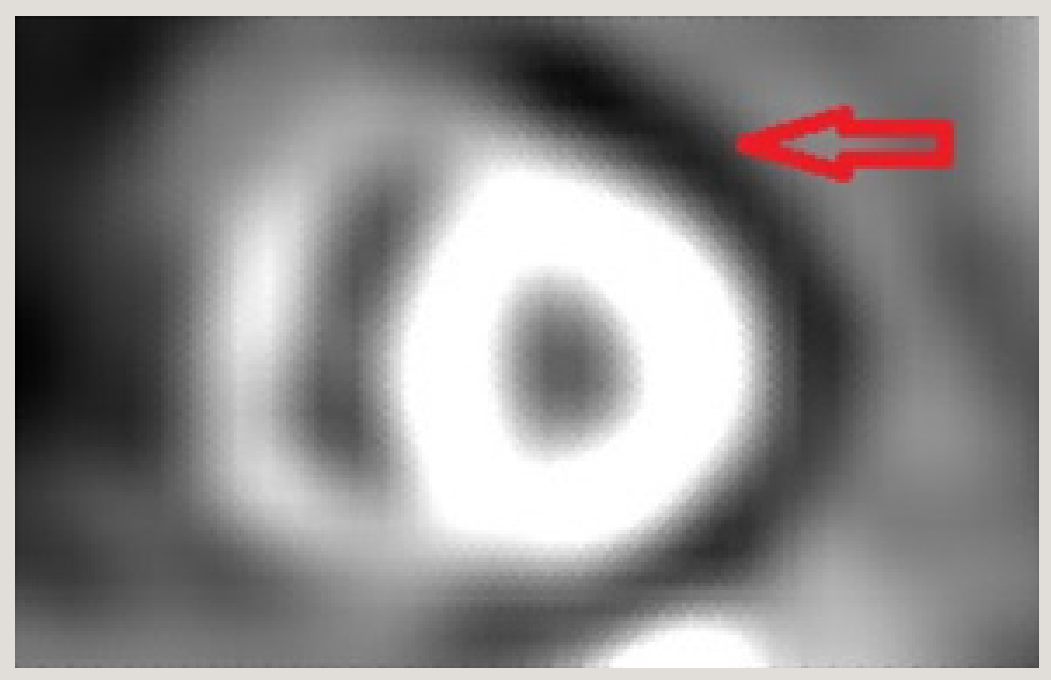

Figure 2 Black and white zoomed stress short axis images shows a clear halo of decreased tracer uptake (arrow) surrounding the left ventricle, consistent with a pericardial effusion on nuclear medicine imaging. There is also increased radiopharmaceutical uptake by the lungs due to an elevated left ventricular end diastolic pressure.

Corresponding author: David Sotello MD Contact Information: David.sotello@ttuhsc.edu DOI: $10.12746 /$ swrccc 2014.0208 .102
A 36-year-old man with diabetes mellitus, hypertension, and end-stage renal disease on hemodialysis underwent a nuclear myocardial perfusion imaging (NMPI) study as part of perioperative evaluation for kidney transplantation. The NMPI study (Tc- 


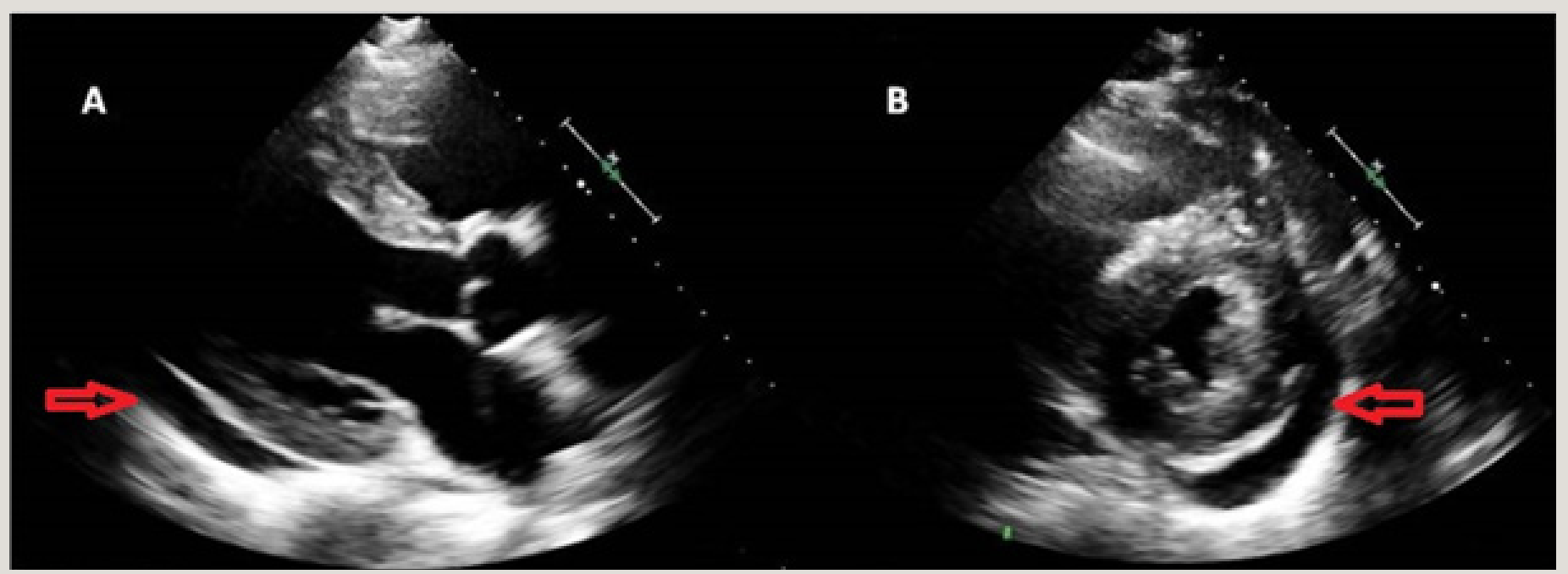

Figure 3 Transthoracic echocardiogram parasternal long axis (A) and short axis (B) views demonstrate moderate size pericardial effusion (arrows) first identified on the nuclear myocardial perfusion study.

99m) demonstrated a "halo" of decreased activity surrounding the myocardium. This was enhanced due to increased lung uptake and was confirmed to be a moderate pericardial effusion with tamponade physiology on transthoracic echocardiogram. The patient had several echocardiograms in the past, but none of them showed evidence of a pericardial disease. Pericardial effusion is uncommonly diagnosed with an NMPI, but in this particular patient it can be clearly seen due to the presence of increased lung uptake of the radiotracer. ${ }^{1-8}$

Author affiliations : Drs Sotello, Trujillo, Soontrapa, and Meyerrose are in the Department of Internal Medicine at TTHUSC. Jennifer Harris (CNMT) works at University Medical Center in Lubbock.

Submitted: $5 / 28 / 2014$

Accepted: 9/9/2014

Reviewers: Scott Shurmur MD

Conflict of Interest: None

Published electronically: 10/15/2014

\section{References}

1. Thind P, Tow D, Drum D, Nagel S. An unexpected pericardial effusion. Clin Nucl Med 2001 Feb; 26(2):171-2. 2. Herzog E, Rasnow N, DePuey G. Diagnosis of pericardial effusion and its effects on ventricular function using gated Tc-99m sestamibi perfusion SPECT. Clin Clin Nucl Med 1998 Jun; 23(6):361-4.

3. Spieth Michael, Schmitz S, Tak T. Incidental Massive Pericardial Effusion Diagnosed by Myocardial Perfusion Imaging. Clin Med Res 2003 Apr; 1(2):141-4.

4. Valdez VA, Jacobstein JG. Visualization of a malignant pericardial effusion with Tc-99m-EHDP. Clin Nucl Med 1980 May; 5(5):210-2.

5. Jeh E, Thompson MA, Meade RC. Accumulation of Tc-99m diphosphonate in pericardial effusion. J Nucl Med 1979 Oct; 20(10):1102-3.

6. Cesani F, Tee H, Esquivel-Avila J, Villanueva-Meyer J. Pericardial effusion in primary hypothyroidism. Tc-99m sestamibi imaging. Clin Nucl Med 1995 May; 20(5):457-8.

7. Patel AD, Abo-Auda WS, Gupta H, Iskandrian AE. Detection of pericardial effusion during Tc-99m sestamibi cardiac imaging. J Nucl Cardiol 2003 Jan-Feb; 10(1):102-4.

8. Staab E, Patton D. Nuclear medicine in patients with pericardial effusion. Semin Nucl Med 3: 191, 1973. 